\title{
Expression Patterns of Developmental Control Genes in Normal and Engrailed-1 Mutant Mouse Spinal Cord Reveal Early Diversity in Developing Interneurons
}

\author{
Michael P. Matise and Alexandra L. Joyner \\ New York University Medical School, Skirball Institute of Biomolecular Medicine, Developmental Genetics Program, \\ New York, New York 10016
}

\begin{abstract}
The vertebrate spinal cord has long served as a useful system for studying the pattern of cell differentiation along the dorsoventral $(\mathrm{d} / \mathrm{v})$ axis. In this paper, we have defined the expression of several classes of genes expressed in restricted $\mathrm{d} / \mathrm{v}$ domains in the intermediate region (IR) of the mouse spinal cord, in which most interneurons are generated. From this analysis, we have found that spinal cord interneurons and their precursors express unique combinations of transcription factors and Notch ligands at the onset of their differentiation. The domains of expression of a number of different classes of genes share similar boundaries, indicating that there could be a basic subdivision of the ventral IR into four distinct regions. This differ-
\end{abstract}

The vertebrate nervous system is organized along both the anterior-posterior $(\mathrm{a} / \mathrm{p})$ and dorsoventral $(\mathrm{d} / \mathrm{v})$ axes. How this regionalization occurs during embryogenesis is currently a major focus of developmental neurobiology. Much of our understanding of the early events in $\mathrm{d} / \mathrm{v}$ pattern formation comes from studies that focus on the development of the spinal cord (for review, see Tanabe and Jessell, 1996). These studies have concentrated primarily on the most ventral and dorsal cells in the spinal cord and the signals that control the specification of these cells. In contrast, despite the fact that the vast majority of neurons in the spinal cord are interneurons, with few exceptions (Shiga and Oppenheim, 1991) the early molecular development of this population of cells is the least well studied.

A growing body of data suggests that cell fates along the $d / v$ axis of the spinal cord are controlled in part by secreted factors emanating from the ventral midline and dorsal non-neural ectoderm. For example, Sonic hedgehog (Shh) has recently been shown to influence floor plate-motoneuron-interneuron cell fate choices in a concentration-dependent manner in an in vitro chick explant assay (Ericson et al., 1996). Thus it seems that the estab-

\footnotetext{
Received June 12, 1997; revised July 30, 1997; accepted August 5, 1997.

M.P.M. is supported by a National Research Service Award Fellowship; A.L.J. is supported by National Institutes of Health. We thank Sunny Chu, Anna Auerbach, and Kasia Losos for technical support. We thank Greg Dressler, Achim Gossler, Peter Gruss, Tom Jessell, Randy Johnson, Gail Martin, Frank Ruddle, and Gerry Weinmaster for providing RNA in situ probes and antibodies, and Gord Fishell, Kenny Campbell, Doug Epstein, and Kamal Sharma for comments on this manuscript. We also thank John Burrill and Martyn Goulding for discussing their results before publication.

Correspondence should be addressed to Alexandra L. Joyner, New York University Medical Center, Skirball Institute of Biomolecular Medicine, Developmental Genetics Program, 540 First Avenue, New York, NY 10016.

Copyright (C) 1997 Society for Neuroscience $0270-6474 / 97 / 177805-12 \$ 05.00 / 0$
}

ential gene expression suggests that spinal cord interneurons acquire unique identities early in their development and that Notch signaling mechanisms may participate in the determination of cell fate along the $d / v$ axis. Gene expression studies in Engrailed-1 (En-1) mutants showed that En-1-expressing and other closely positioned classes of neurons do not require the homeodomain protein En-1 for their early pattern of differentiation. Rather, it is suggested that En-1 may function to distinguish a subset of interneurons during the later maturation of the spinal cord.

Key words: Engrailed-1; interneurons; Notch ligands; spinal cord; transcription factors; expression patterns lishment of distinct differentiated cell identities along the $d / v$ axis during development is an important mechanism for generating neuronal diversity in the spinal cord.

In the mouse spinal cord, neural differentiation largely takes place between 9 and $15.5 \mathrm{~d}$ postcoitum (dpc), beginning rostrally at $\sim 9.0 \mathrm{dpc}$ and progressing caudally (Nornes and Carry, 1978). There is also a ventral to dorsal gradient of cell differentiation, with the majority of ventral cell types being born before $12.5 \mathrm{dpc}$. To begin to examine the early development of spinal cord interneurons, we have focused on interneurons generated in the intermediate region (IR) of the spinal cord, here defined as the area between the dorsal and ventral horns, during the early stages of cell differentiation at 9.5-11.5 dpc. We have studied the expression of three homeobox-containing transcription factors with restricted domains of expression in post-mitotic cells of the IR: En-1 (Joyner et al., 1985), Evx-1 (Bastian and Gruss, 1990), and Lmx-1 (R. Johnson, unpublished data). We have also analyzed the expression of three genes expressed in the ventricular zone (VZ): the Notch ligands Jagged-1 (Lindsell et al., 1995) and Dll-1 (a mouse Delta homolog) (Bettenhausen et al., 1995) and the homeobox gene $D b x-1$ (Shoji et al., 1996). This analysis has revealed that interneurons and their precursors in the early IR express unique combinations of genes in similar $\mathrm{d} / \mathrm{v}$ domains at the onset of their differentiation. Although it is known that interneurons in the mature spinal cord can be grouped according to similar characteristics, such as morphology, projections, or physiology (Jankowska and Lundberg, 1981), these observations suggest that different classes of interneurons may share early molecular identities and that Notch signaling may participate to generate diversity among interneurons along the $d / v$ axis. Furthermore, the expression patterns of many genes respect similar boundaries, suggesting the existence of fundamental domains of cell differentiation in the developing spinal cord. 
We have also begun to examine the role of En-1 in spinal cord interneurons by studying in detail the development of En-1 interneurons at $9.5-15.5 \mathrm{dpc}$ by analyzing gene expression in En-1 mutants. We have found that $E n-1$ and other ventral interneurons do not require En-1 function for their early survival or differentiation. This analysis suggests that the early onset of En-1 expression in differentiating interneurons may serve a later function in distinguishing this population of interneurons within this broad class of cell type in the spinal cord.

\section{MATERIALS AND METHODS}

Generation of mice. The generation of En-1 ${ }^{l k i}$ (lacZ knock-in) embryonic stem (ES) cells and chimeric mice in which the bacterial gene coding for $\beta$-galactosidase ( $\beta$-gal), lac $Z$, is inserted into the $E n-1$ locus has been described previously (Hanks et al., 1995). Using En-1 ${ }^{1 \mathrm{ki} /+}$-targeted ES cells, we generated mouse lines using two independently targeted cell lines. Male chimeras were made using morula aggregation as described by Nagy et al. (1993) and bred with CD1 females (Charles River Laboratories, Wilmington, $\mathrm{MA}$ ) to transmit the allele through the germline.

Homozygote En-1 $1 \mathrm{ki} / \mathrm{ki}$ embryos were obtained by intercrossing heterozygote mice at F2-F6 generations. The lines were maintained on an outbred CD1 background. En-1 ${ }^{1 \mathrm{ki} / \mathrm{ki}}$ embryos were morphologically indistinguishable from $E n-1$ hd/hd (homeodomain deletion) null mutant mice (Wurst et al., 1994) and were identified by genotyping using yolk sac DNA or by morphological criteria as described previously (Wurst et al. 1994). To obtain En-1 ${ }^{\text {lki/hd }}$ embryos, heterozygous $E n-1^{1 \mathrm{ki} /+}$ and $E n-1$ $\mathrm{hd} /+$ mice were crossed. Noon on the day of vaginal plug was designated as $0.5 \mathrm{dpc}$. For mutant analysis, we compared at least $6-10$ embryos at all stages with wild-type littermates.

Immunohistochemistry. Embryos were collected in Dulbecco's PBS (D-PBS) containing $\mathrm{Mg}^{2+}$ and $\mathrm{Ca}^{2+}$ (Cellgro) on ice and then fixed for $30 \mathrm{~min}$ to $2 \mathrm{hr}$ in $4 \%$ paraformaldehyde $(\mathrm{PF}) / \mathrm{D}-\mathrm{PBS}$. Tissue was then sunk in $30 \%$ sucrose/D-PBS, frozen in Tissue Tek, and sectioned at $12-16 \mu \mathrm{M}$ in a cryostat. Sections were collected on Fisher Colorfrost-Plus slides, air-dried for $\sim 1 \mathrm{hr}$, and stored at $-20^{\circ}$ until used.

For antibody staining, sections were brought to room temperature and then fixed for $5 \mathrm{~min}$ in $4 \% \mathrm{PF}$. After sections were washed $3 \times 5 \mathrm{~min}$ in D-PBS, they were blocked with D-PBS containing $10 \%$ normal goat serum (NGS), $0.1-0.4 \%$ Triton X-100 for $1 \mathrm{hr}$ at room temperature. Antibodies were applied in a buffer containing $1 \%$ NGS, $0.1-0.4 \%$ Triton X-100 in D-PBS. Primary antibodies used and dilutions were as follows: rabbit anti-Engrailed ( $\alpha$-Enhb-1), 1:500; mouse anti-Lim-1/2 (4F10), 1:2; rabbit anti-Pax-2, 1:200; mouse anti- $\beta$-tubulin (TuJ1), 1: 5000; rabbit anti- $\beta$-gal $\left(5^{\prime}-3^{\prime}\right.$, Inc.), 1:500; mouse antibromodeoxyuridine (BrdU) (Sigma, St. Louis, MO), 1:250. All primary incubations were overnight at $4^{\circ} \mathrm{C}$. In double-labeling experiments using monoclonal and polyclonal antibodies, primary antibodies were mixed and incubated together overnight. Secondary antibodies (Jackson ImmunoResearch, West Grove, PA) and dilutions were as follows: fluorescein-conjugated goat anti-rabbit and goat anti-mouse IgG, 1:100; Cy-3-conjugated goat anti-rabbit and goat anti-mouse IgG, 1:200. After staining, sections were dehydrated in graded ethanols, washed in xylene, and coverslipped with Permount (Fisher Scientific, Houston, TX). Fluorescent antibody-labeled sections were coverslipped using Gelmount (biomeda Corp.), and viewed under epifluorescence.

For double-labeling with $\beta$-gal and antibodies on sections, $\beta$-gal activity was visualized before antibody labeling as follows: sections were washed in PBS containing $0.1 \%$ Tween-20 (PBT) and then incubated in 5 -bromo-4-chloro-3-indolyl $\beta$-D-galactopyranoside (X-gal) (Sigma) solution at $37^{\circ}$ for $6-8 \mathrm{hr}$. After this, sections were washed in PBT twice and then in PBS. Antibody labeling was then performed as described above.

RNA in situ hybridization. Whole-mount RNA in situ hybridization of embryos was performed as described (Parr et al., 1993), with modifications (Knecht et al., 1995). Antisense riboprobes used were Pax-2 (Dressler et al., 1990), Evx-1 (Dush and Martin, 1992), Dbx-1 (Shoji et al., 1996), Lmx-1 (R. Johnson, unpublished), Jagged-1 (Lindsell et al., 1995), and Dll-1 (Bettenhausen et al., 1995). At least three to four normal and 3-4 En-1 mutants embryos were examined at $9.5,10.5$, and $11.5 \mathrm{dpc}$ for each probe. For whole-mount double-labeling with $\beta$-gal and in situ hybridization, $\beta$-gal activity was visualized before in situ hybridization. Embryos were collected and fixed as described above, washed in PBT, and incubated in X-gal for $6-8 \mathrm{hr}$ at $37^{\circ}$. After this, embryos were washed $3 \times 10 \mathrm{~min}$ in PBT and refixed overnight in $4 \% \mathrm{PF}$. Embryos were stored in PBS at $4^{\circ} \mathrm{C}$ until whole-mount in situ hybridization was performed, as described above, except that the methanol dehydration and peroxide bleaching steps were omitted.

For sectioning after whole-mount staining, embryos were embedded in $4 \%$ agarose and sectioned on a Leica VT-1000E Vibratome at 50-75 $\mu \mathrm{M}$, mounted on Fisher Colorfrost Plus slides, and air-dried. The entire spinal cord was sectioned in all cases. Sections were counterstained with Nuclear Fast Red, dehydrated, and coverslipped.

Retrograde axon labeling. Wild-type CD1 embryos were collected in cold PBS and then transferred to L-15 medium (Leibovitz's, without glutamine, from Specialty Medium) on ice. Embryos were decapitated and eviscerated, and ventral laminectomies were performed. Fluorescein- or rhodamine-conjugated, lysinated dextran, $3 \mathrm{kDa}$ molecular weight (Molecular Probes, Eugene, OR), dissolved in PBS containing $1 \%$ Triton X-100, was pressure-injected into the ventral midline or ventrolateral marginal zone-white matter using a glass microcapillary pipette (tip diameter of $\sim 50 \mu \mathrm{M}$ ). Spinal cords were incubated for $4-6 \mathrm{hr}$ at room temperature in L-15 medium, after which they were fixed in $4 \%$ $\mathrm{PF}$ on ice for $30 \mathrm{~min}$ to $1 \mathrm{hr}$. Embryos were then processed for cryosectioning and antibody detection as described above.

$B r d U$ labeling and detection. Two pregnant CD1 females were injected intraperitoneally with a $20 \mathrm{mg} / \mathrm{ml}$ solution of BrdU (Sigma) in PBS, 2 and $4 \mathrm{hr}$ before they were killed. Litters (12-15 embryos each) were collected and processed for antibody detection as described above. For detection of BrdU, a mouse monoclonal antibody to BrdU (Sigma) was used at 1:250 after sections were incubated for $40 \mathrm{~min}$ in $2 \mathrm{~N} \mathrm{HCl}$. For double-labeling, incubation with X-gal was performed before antibody detection of BrdU.

Image analysis and processing. Fluorescent images were visualized on a Zeiss Axioskop microscope equipped with epifluorescence and a Princeton Instruments cooled-CCD camera. Double-labeled sections were collected using different filter sets, and color encoding and image superimposition were performed using Metamorph image processing software (Universal Imaging Corporation, West Chester, PA). Raw digital images were processed in Adobe Photoshop.

Histological sections were photographed on a Leitz DMRXE compound microscope with Kodak Ektachrome 64T or 160T slide film. Digital images were made by scanning slides on a Nikon LS3510AF film scanner and processed in Adobe Photoshop. Most images were corrected for color balance, contrast, brightness, or cropping using Adobe Photoshop, but no other modifications were made.

\section{RESULTS}

\section{Interneurons express unique transcription factors at the early stages of their differentiation}

Previous studies have shown that En-1 (Davis et al., 1991) and Evx-1 (Bastian and Gruss, 1990) are expressed in the developing spinal cord. In this report, we have analyzed the expression of these genes in relation to one another, and to a third gene expressed in the spinal cord, Lmx-1, a member of the LIMdomain transcription factor family.

The expression of En-1, Evx -1, and Lmx-1 was first seen in the spinal cord beginning at $9.5-10.5 \mathrm{dpc}$ in the IR, a region that lies between the dorsal and ventral horns and contains primarily interneurons. At this stage of development, spinal cord cells are beginning to differentiate, moving from the VZ to the intermediate zone (IZ) in the process. To directly compare the early expression domains of these genes, we used a targeted mouse line, $E n-1^{1 \mathrm{ki} /+}$, in which the bacterial reporter gene lac $Z$ was inserted into the first exon of En-1 (Hanks et al., 1995) (also see Materials and Methods). The expression of $\beta$-gal in heterozygous En-1 ${ }^{1 \mathrm{ki} /+}$ mice was found to be almost identical to normal En-1 expression in the spinal cord, as determined by double-labeling using X-gal to detect $\beta$-gal and En antibodies to detect En- 1 protein, and thus serves as a faithful reporter of $E n-1$ expression (data not shown). By using double-labeling with X-gal to detect $\beta$-gal $(E n-1)$ and RNA in situ analysis to detect $E v x-1$ or $L m x-1$ in the same embryos, we were able to accurately establish the domains of gene expression, using the domain of En-1 expression as a reference point along the $\mathrm{d} / \mathrm{v}$ axis. 
At $10.5 \mathrm{dpc}$, expression of $E v x-1$ was detected in a cluster of cells located dorsal to and not overlapping $\beta$-gal (En-1)expressing cells in the IZ (Fig. $1 a$ ). This relationship was seen at all rostrocaudal levels of the spinal cord and hindbrain at 10.5 and $11.5 \mathrm{dpc}$. The detection of $E v x-1$ at the lateral margins of the VZ strongly suggests that it is expressed in postmitotic cells. Thus, $E n-1$ and Evx-1 are expressed in nonoverlapping, adjacent populations of early neurons in the ventral IR. In addition, the rostral boundary of expression of $E v x-1$ at the border of rhombomeres (r) 1 and 2 in the hindbrain corresponds precisely with the rostral boundary of En-1 expression (data not shown). These complementary but similar patterns suggest a related mechanism for regulating the early expression of $E n-1$ and $E v x-1$ in postmitotic cells of the ventral spinal cord and hindbrain.

The domain of $L m x-1$ expression was also found in cells of the IZ, located immediately dorsal to the developing sulcus limitans at $10.5 \mathrm{dpc}$ (Fig. 1b). Lmx-1 expression is separated from En-1expressing cells by a gap, only a portion of which is occupied by Evx-1-expressing cells (Fig. 1c). In contrast to En-1 and Evx-1, the rostral boundary of $L m x-1$ expression in this domain does not end at the $\mathrm{r} 1-\mathrm{r} 2$ border in the hindbrain but instead continues through $\mathrm{r} 1$ into the midbrain (data not shown).

These observations show that differentiating interneurons in the ventral two thirds of the IR express unique domains of gene expression along the d/v axis: $E n-1$ the most ventral, followed by $E v x-1$ and then $L m x-1$. The presence of gaps in expression reveals the existence of two additional domains in the ventral IR, located between Evx-1 and Lmx-1 (Fig. 1c) and En-1 and Islet-1 (data not shown).

\section{The En-1 and Evx-1 expression domains correspond to ventral domains of Jagged-1 and DII-1 expression}

The expression patterns of the Notch ligands Jagged-1/Serrate and Delta-1/Dll-1 in the vertebrate spinal cord have been described in several recent studies (Lindsell et al., 1995, 1996; Myat et al., 1996). To compare the expression domains of Jagged-1 and Dll-1 in the VZ with domains of gene expression in the IZ, we used double X-gal/in situ analysis in En-1 ${ }^{1 \mathrm{ki} /+}$ mice. This analysis revealed that the region of the neuroepithelium from which $E n$ 1 -expressing cells derive corresponds precisely to the ventral Jagged-1 stripe in the VZ throughout the spinal cord and hindbrain at 10.5 and $11.5 \mathrm{dpc}$ (Fig. $1 d$ ). In addition, the rostral limit of this ventral Jagged-1 stripe was at the r1-r2 border, corresponding to the rostral limit of En-1 expression (data not shown). The dorsal Jagged-1 stripe was also located in the VZ just ventral to the sulcus limitans and to the $L m x-1$ domain, which is located dorsal to the sulcus limitans (Fig. 1e), in the region that does not correspond to the domains of expression of En-1, Evx-1, or Lmx-1. This dorsal Jagged-1 stripe extends rostrally through r1 into the midbrain (data not shown).

We have also compared the expression domains of Dll-1 and $E n-1$ in the spinal cord. As reported previously, there is a gap in the expression of Delta- 1 in the ventral VZ of the rat (Lindsell et al., 1996). Comparison of En-1 and Dll-1 expression revealed that this gap in Dll-1 expression corresponds to the region where En-1 expression is seen (Fig. 1f). Dll-1 expression dorsal to this domain is continuous up to the roof plate. Because we have shown above that the $E v x-1$ and $L m x-1$ expression domains lie dorsal to the $E n-1$ domain, and that Dll-1 expression in the VZ is also immediately dorsal to En-1, it can be inferred that Evx-1 and $L m x-1$ derive from a region of the neuroepithelium in which $D l l-1$ is expressed. Taken together, these results suggest a potential role for Jagged-1 and Dll-1 in establishing and/or maintaining the pattern of cell differentiation along the $d / v$ axis in postmitotic interneurons of the mouse IR.

\section{$D b x-1$ is expressed in the intermediate zone in a domain dorsal to En-1}

The expression of $D b x-1$ has recently been described in the spinal cord using both RNA in situ analysis (Shoji et al., 1996) and $D b x$-1-enhancer-element-driven lacZ expression (Lu et al., 1996). These studies show that $D b x-1$ expression can be seen as early as $9.5 \mathrm{dpc}$ extending in continuous, bilateral stripes in the $\mathrm{VZ}$ along the length of the spinal cord and hindbrain. To compare the domains of $D b x-1$ and En-1 expression, we again made use of $\mathrm{X}$-gal/in situ double-labeling. Analysis of expression at 9.5-11.5 dpc revealed that $D b x-1$ was expressed in a domain located immediately dorsal to En-1 at all rostrocaudal levels, similar in position along the $\mathrm{d} / \mathrm{v}$ axis to the $E v x-1$ expression domain but extending into the VZ (Fig. $1 g$ ). At 9.5 dpc, $D b x-1$ expression was seen along the entire length of the neural tube, whereas En-1 expression was detected only in more rostral regions (midthoracic and higher) (Davis et al., 1991) (data not shown). Because of the rostrocaudal progression of maturation in the spinal cord, this observation shows that $D b x-1$ expression precedes $E n-1$ expression in the spinal cord. In addition, $D b x-1$ expression in this domain spans both the VZ and IZ (Fig. 1g). These observations suggest that $D b x-1$ may be expressed in both dividing and postmitotic cells and that $D b x-1$ may play a role in establishing a position along the $\mathrm{d} / \mathrm{v}$ axis at stages preceding cell differentiation.

\section{En-1 is expressed in postmitotic ventral interneurons}

To begin to examine the role of transcription factors in spinal cord interneurons, we have analyzed the cells expressing En-1 in more detail in normal and En-1 mutant mice. We have also analyzed gene expression in other populations of spinal cord interneurons in the En-1 mutant.

Previous studies showing En-1 expression in the IR at the lateral margins of the $\mathrm{VZ}$ and its progression from rostral to caudal as cell differentiation is occurring in the spinal cord suggest that En-1 is first expressed as cells become postmitotic (Davis and Joyner, 1988; Davis et al., 1991). To confirm this, and to determine whether En-1 expressing cells are neurons, two markers were used; a neuron-specific form of tubulin, $\beta$-IIItubulin, which identifies postmitotic neurons (Lee et al., 1990), and BrdU, which identifies proliferating cells (Gratzner, 1982; Nowakowski et al., 1989). In the following analyses, we have used a polyclonal antiserum that detects both En-1 and En-2 proteins (Davis et al., 1991); however, En-2 expression is never detected in the embryonic mouse spinal cord (Davis and Joyner, 1988), and thus this antibody reveals only En-1 expression. At $9.5-10.5 \mathrm{dpc}$, En protein was detected in the nucleus of cells located at the lateral margins of the VZ, as well as in a few cells located close to the lumenal surface. Most, if not all, En-expressing cells also expressed $\beta$-tubulin (Fig. $2 a$ ), indicating that they are postmitotic neurons. To confirm that they are postmitotic, short pulses (2-4 hr before mice were killed) of BrdU labeling were used to mark mitotically active neuroepithelial cells. Of four embryos examined from two separate litters, En expression was not detected in cells that had incorporated BrdU, confirming that the expression of En-1 is initiated in postmitotic neurons (Fig. 2b). En immunoreactivity was detected occasionally in cells close to the lumenal surface; however, these cells seemed to have just completed their final division close to the ventricle, because En staining was not 

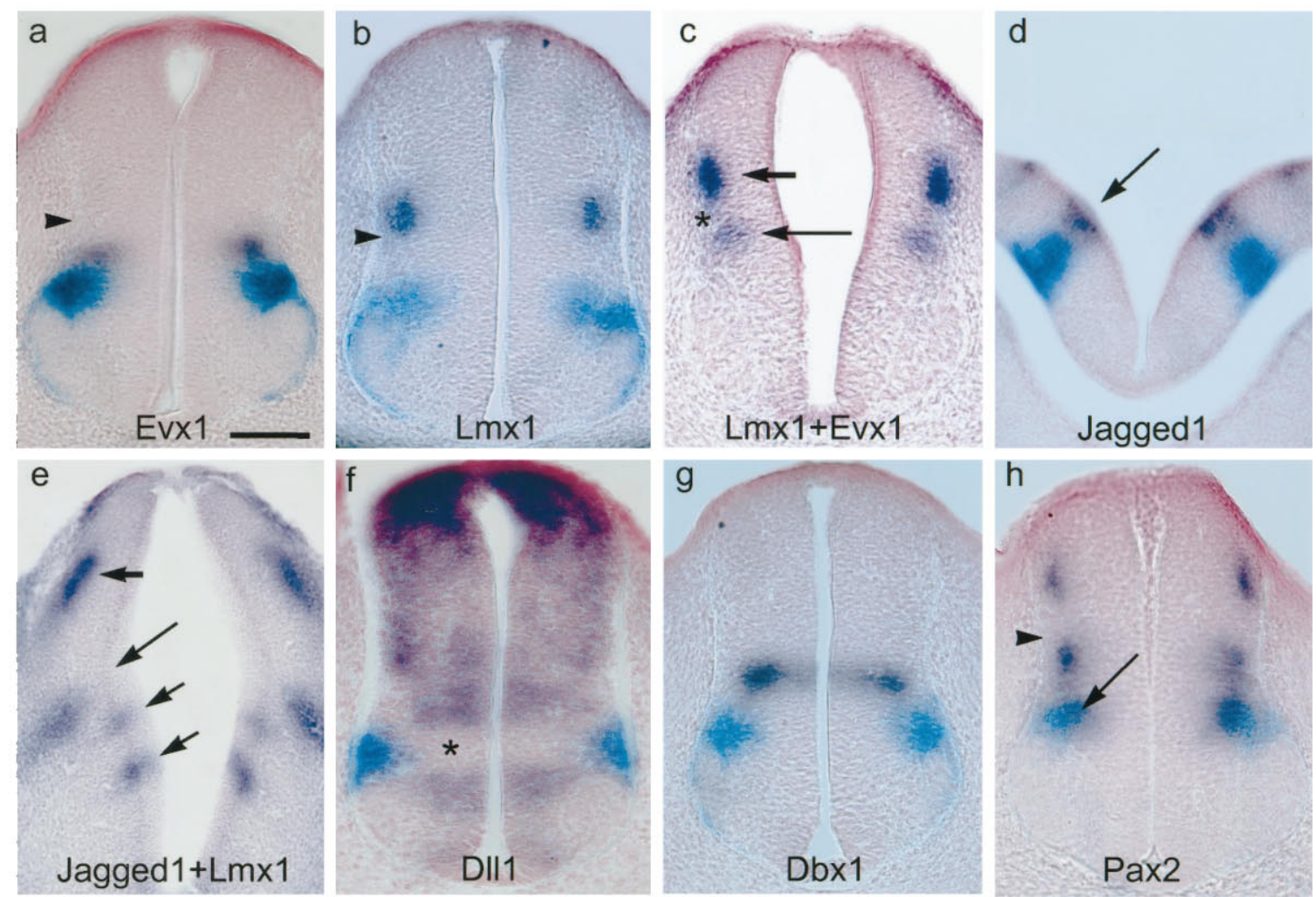

\section{FIGURE 1}
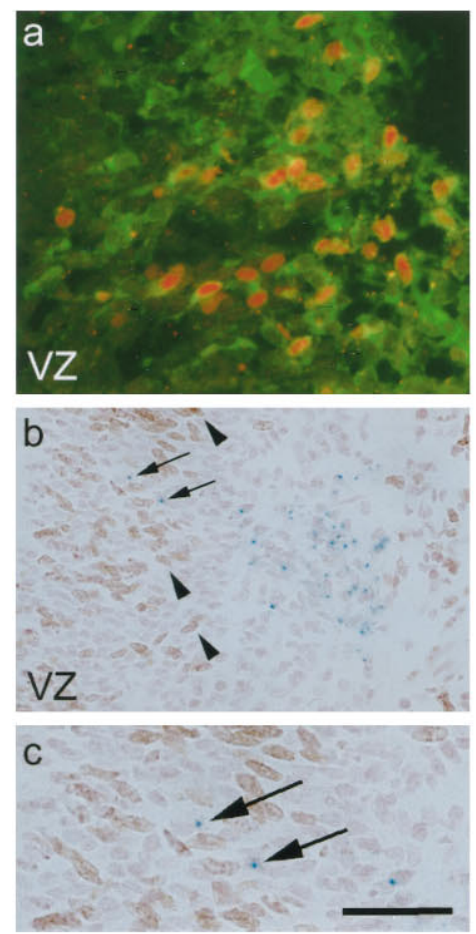

FIGURE 2
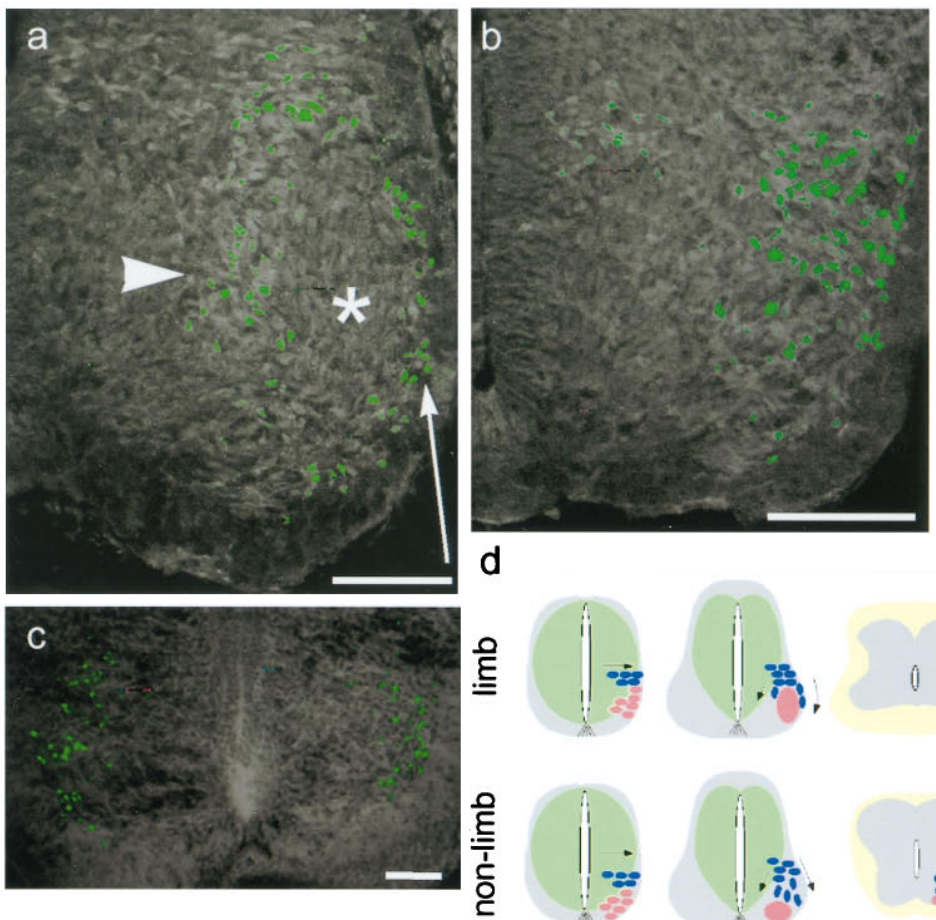

FIGURE 3

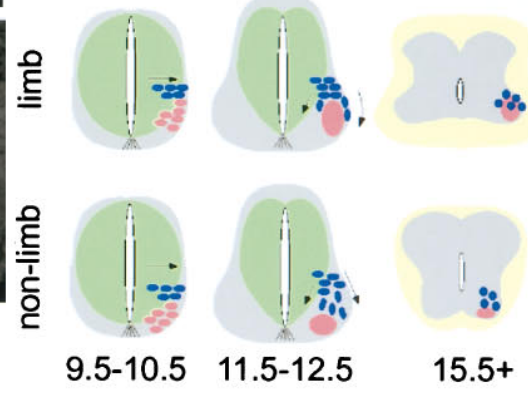


observed independent of $\beta$-tubulin or in conjunction with BrdU labeling.

The expression pattern of En-1 was also analyzed at later stages of spinal cord development. At 10.5-15.5 dpc, En immunoreactivity was detected in a group of cells located at roughly the same $\mathrm{d} / \mathrm{v}$ position as at earlier stages (Fig. 3). In addition, many Enexpressing interneurons were located more ventrally. Cells in the IR of the spinal cord are generated in an outside-to-inside manner, with lateral cells being born largely before medial ones (Nornes and Carry, 1978). Analysis of the expression of En-1 in ventral cells over time showed that the more ventrally located, En-1-expressing cells were first detected at the lateral margins of the spinal cord at $\sim 10.5 \mathrm{dpc}$, whereas more medially, ventrally located En-1-expressing cells only began to appear at $\sim 11.5 \mathrm{dpc}$. These observations suggest that as $E n-1$ cells are generated, many begin a ventral migration as they mature. In the regions of the spinal cord containing a lateral motor column (LMC), the majority of ventrally migrating En-1-expressing interneurons were lateral and medial to motoneurons, whereas some were found in the LMC among motoneurons (Fig. $3 a$ ). In contrast, in nonLMC-containing regions (e.g., midthoracic), En-1 cells instead were more diff usely situated in the ventral horn (Fig. 3b). After the majority of motoneuron cell death has occurred in the mouse spinal cord, at $15.5 \mathrm{dpc}$ (Lance-Jones, 1982), these rostrocaudal differences in $E n-1$ expression are much less pronounced; many En-1 interneurons were found at the same d/v position as where they were generated, as well as ventrolaterally in the ventral horns (Fig. 3c). These observations might be explained by the lateral migration of some medially located $E n-1$ cells before $15.5 \mathrm{dpc}$. It is also possible that $E n-1$ is upregulated in some ventral horn interneurons at these stages. In either case, it seems that there are differences in the migration patterns of En-1 interneurons along the $\mathrm{a} / \mathrm{p}$ axis of the spinal cord, and that these early region-specific migration patterns may be influenced by the number and kind of motoneurons. These early patterns are summarized in Figure $3 d$.

To identify the projections of En-1 interneurons, a fluorescentdextran tracer ( $3 \mathrm{kDa}$ dextran) was injected into the ventral commissure at the midline and ventrolateral funiculus to label commissural and ipsilateral/association interneurons, respectively
(Silos-Santiago and Snider, 1992, 1994). These injected embryos were then processed for En immunoreactivity. In the vast majority of injections, we were unable to detect any En-1-expressing cell that clearly co-labeled after retrograde tracing of these two major classes of interneurons (Fig. 4) $(n=4-8$ embryos each at $11.5,12.5$, and $13.5 \mathrm{dpc}$ ). In a few cases we observed $3 \mathrm{kDa}$ dextran labeling of En-1-expressing interneurons after injection into the ventrolateral funiculus; however, it is likely that such labeling resulted from the uptake of tracer by cells from their leading process during their migration out of the VZ, because they were very few in number and were only found near the injection site (Fig. 4b, arrow). In addition, En-1 expression was detected in some cells that had been labeled by $3 \mathrm{kDa}$ dextran injections directly into the ventrolateral gray matter (data not shown). These observations taken together suggest that En-1 interneurons are more likely to be locally projecting, or to project in the ventral white matter in the vicinity of the ventral roots or wholly within the gray matter.

\section{En-1 marks a subset of $\operatorname{Lim}-1 / 2$, and Pax-2-expressing interneurons}

To further characterize the class of neurons that express $E n-1$, we compared its expression with other markers of IR cell types. At $9.5 \mathrm{dpc}$, the expression of the LIM-domain genes Lim-1 and Lim-2 are confined to cells in the IR (Fujii et al., 1994; Tsuchida et al., 1994). We compared the expression of En-1 with Lim-1 and Lim-2 using both double-label X-gal/RNA in situ and antibody analysis. Using in situ probes specific for Lim-1 or Lim-2, we found that En-1 expression was detected at the ventral limit of both the Lim-1 and Lim-2 expression domains (data not shown). At this stage Lim-1 and Lim-2 expression overlap completely in this domain. Using an antibody that detects both Lim-1 and Lim-2 proteins (Tsuchida et al., 1994), we found that En-1 was expressed in a subset of Lim-1/2-expressing cells at all stages examined and that all En-1 interneurons also express Lim-1/2 proteins (Fig. 5).

At the onset of expression at $9.5 \mathrm{dpc}, E n-1$ expression marked the ventral limit of Lim-1/2 expression (Fig. 5c). At 10.5-11.5 dpc, both En-1 and Lim-1/2 expression became more widespread. The ventrally located, likely migrating En-1-expressing cells continued

$\leftarrow$

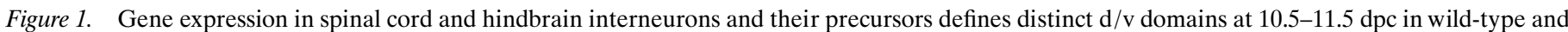

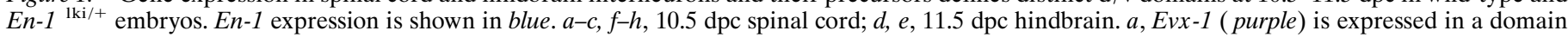

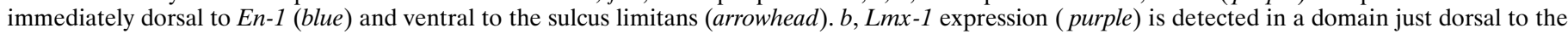

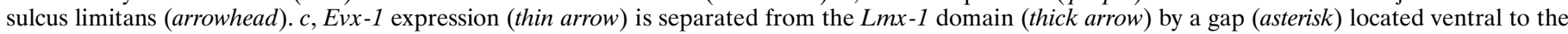

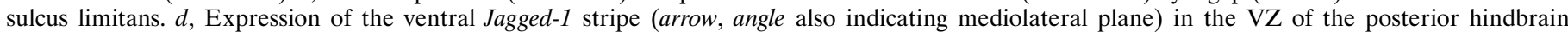

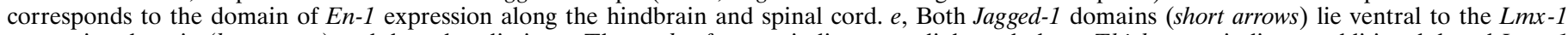

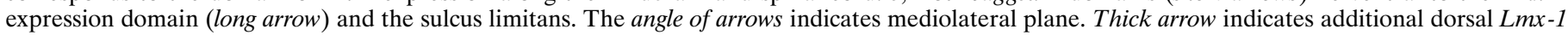

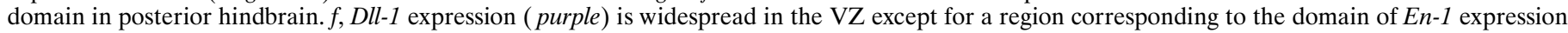

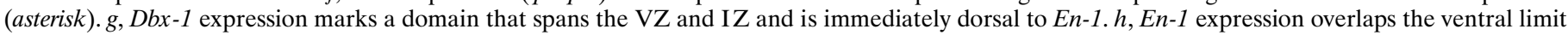

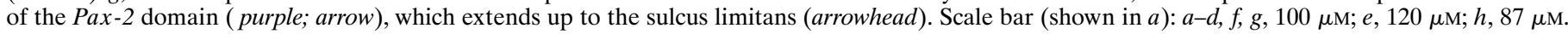

Figure 2. En-1 expression is detected in postmitotic neurons. $a$, In posterior regions of the spinal cord at $10.5 \mathrm{dpc}$, En-1 protein (red) is detected in the nuclei of cells that are migrating out of the VZ. En-1-expressing cells also express $\beta$-tubulin ( green), identifying them as differentiating neurons. $b$, En- 1 interneurons (blue $\beta$-gal staining in En-1 ${ }^{\mathrm{lki} /+}$ embryos) do not incorporate BrdU (brown nuclei, arrowheads), indicating that they are postmitotic. $c$, Enlargement of section shown in $b$. Arrows in $b$ and $c$ indicate En-1 interneurons migrating out of the VZ. Section through the midlumbar region of a $10.5 \mathrm{dpc}$ embryo. Lateral is to the right in both images. VZ, Ventricular zone. Scale bar (shown in $c$ ): $a, 100 \mu \mathrm{M} ; b, 50 \mu \mathrm{M} ; c, 25 \mu \mathrm{M}$.

Figure 3. The expression of En-1 over time suggests that En-1-expressing interneurons undergo a region-specific ventral migration. $a$, In the lumbar spinal cord at $11.5 \mathrm{dpc}$, many En-1-expressing cells ( green) are detected lateral (arrow) and medial (arrowhead) to motoneurons (asterisk). $b$, At the same stage in midthoracic regions, En-1-expressing cells are found throughout the ventrolateral ventral horn. $c$, At 15.5 dpc, En-1-expressing interneurons (green) are widely dispersed in the ventrolateral gray matter of the spinal cord. Shown are transverse sections through the lower thoracic spinal cord. $d$, Summary of the predicted early migration paths of En-1 interneurons. In this schematic, the migration of En-1 cells (blue) is depicted in relation to motoneurons ( pink) at thoracic (bottom) and lumbar (top) levels. Arrows indicate possible migratory routes of En-1 interneurons. Lateral is to the right in $a$ and $b$. Scale bars: $a, b, 50 \mu \mathrm{M} ; c, 100 \mu \mathrm{M}$. 

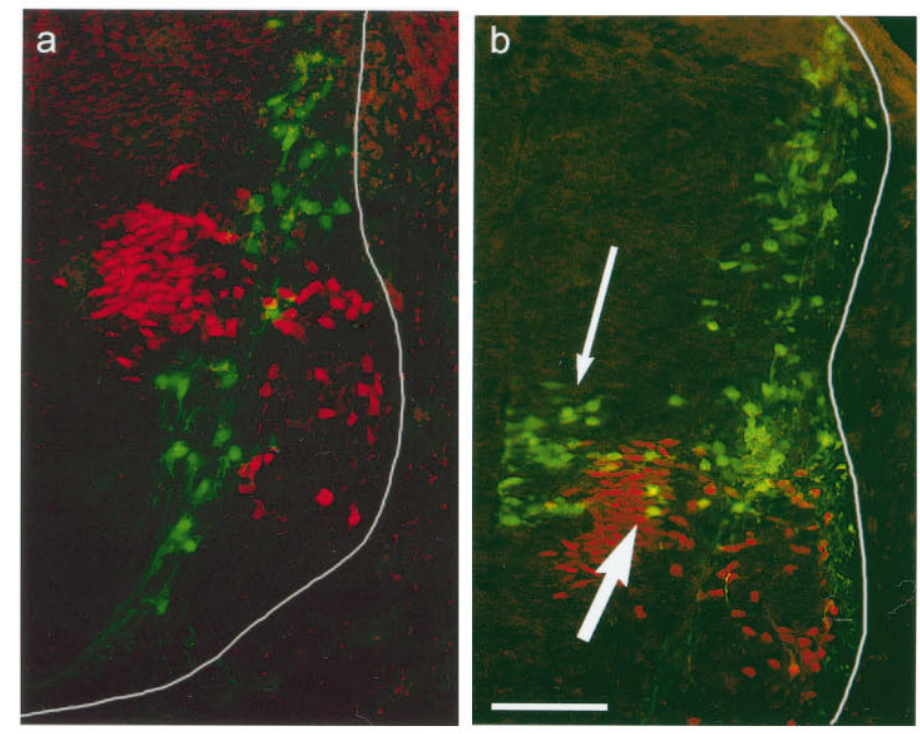

FIGURE 4
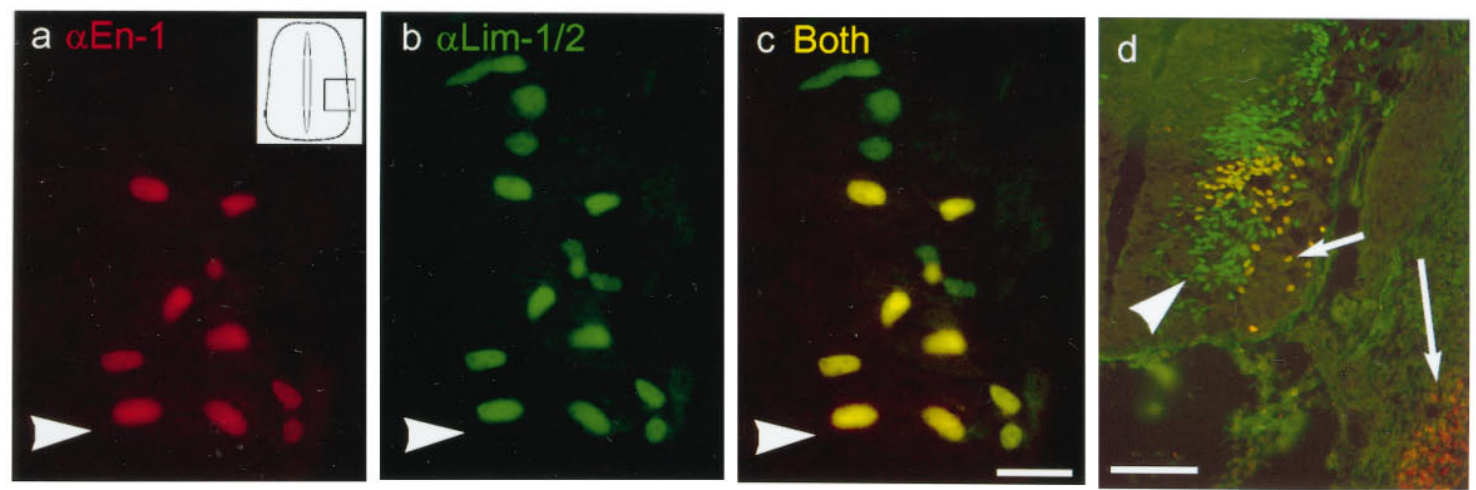

FIGURE 5
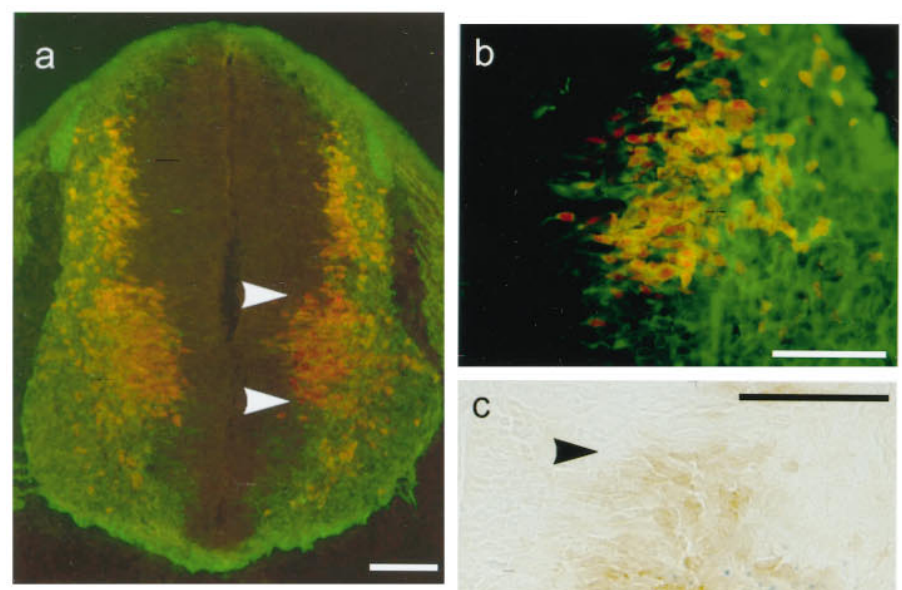

C

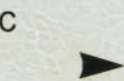

$\alpha$ Pax-2 $+\beta$-tubulin

FIGURE 6

En1+Pax2 
to express Lim-1/2 (Fig. 5d). These ventrally located En-1expressing cells did not, however, express motoneuron markers such as Islet-1/2 proteins at any stage examined (data not shown), in agreement with previously published findings (Pfaff et al., 1996). At $11.5 \mathrm{dpc}$, many additional Lim-1/2-expressing cells were detected ventral to the region where En-1 and Lim-1/2 initially overlapped. These Lim-1/2-expressing cells did not express En-1 (Fig. 5d, arrowhead). By analogy to the chick, these cells may be Lim-1-expressing motoneurons that are migrating through earlier born motoneurons to take up a more superficial position in the lateral motor column (Tsuchida et al., 1994).

The paired box-containing gene $\mathrm{Pax}-2$ has also been shown to be expressed broadly in the IR of the spinal cord during the early stages (9.5-11.5 dpc) of cell differentiation (Fig. 6a) (Nornes et al., 1990). At the onset of its expression, Pax-2 protein is detected at the margins of the $\mathrm{VZ}$ in two domains: beginning dorsal to the ventral horn motor column and extending up to the sulcus limitans, and in a second domain in the developing dorsal horn (Fig. 6a). Pax-2-expressing cells also expressed $\beta$-tubulin and are thus postmitotic neurons (Fig. 6a,b). Using double-labeling in whole embryos, we found that $\beta$-gal $(E n-1)$ expression overlapped the ventral limit of the region of the IR in which Pax-2 RNA was expressed (Fig. 1h). To determine whether En-1 and Pax-2 are expressed in the same cells, we used two different methods. First, we examined sections from En-1 ${ }^{1 \mathrm{ki} /+}$ embryos stained with X-gal and Pax-2 antibody. This analysis reveals that there is extensive overlap between En-1 ( $\beta$-gal) and Pax-2-expressing cells in the ventral IR (Fig. $6 c$ ). Second, we compared the expression of Pax-2 and Lim-1/2 proteins in wild-type sections at $10.5 \mathrm{dpc}$. We found that Pax-2 and Lim-1/2 proteins are coexpressed in cells of the ventral IR at the onset of their expression at this stage (Fig. 7a-c). Because we have shown above that all En-1 interneurons express Lim-1/2 proteins in the ventral IR, we can infer that En-1 interneurons also express Pax-2 proteins in this same domain.

We have also found that the dorsal limit of expression of Pax-2 and Lim- $1 / 2$ is coincident at $9.5-10.5 \mathrm{dpc}$, extending up to the sulcus limitans (Fig. $7 d-f$ ) and abutting the $L m x-1$ domain (data not shown). At $11.5 \mathrm{dpc}$, the expression of Lim-1/2 and Pax-2 diverges significantly; in the ventral horn many cells appear that express only Pax- 2 or Lim-1/2 proteins, but not both, although many other cells in the IR continue to express both proteins. In addition, the domains of expression of Pax-2 and Lim-1/2 only partially overlap in the dorsal horns (data not shown). Thus it seems that the early expression of Pax- 2 and Lim-1/2 overlaps in the IR but not at later times in more ventral or dorsal regions of the spinal cord. Furthermore, En-1 expression marks the ventral boundary of this region of overlapping Pax-2 and Lim-1/2 expression in the IR.

\section{En-1 is not required for the survival or early differentiation of En-1-expressing cells}

We have shown that interneurons in the spinal cord express unique transcription factors along the $\mathrm{d} / \mathrm{v}$ axis, dividing the ventral IR into at least four ventral domains. As a first step in exploring the role of these genes in interneuron identity, we have analyzed the pattern of gene expression in the ventral spinal cord in the absence of En-1 gene function.

$E n-1$ is expressed in the midbrain-hindbrain region beginning at $\sim 8.5 \mathrm{dpc}$, in addition to its expression in the spinal cord and hindbrain (Davis et al., 1991). Mice lacking En-1 function have a loss of midbrain and cerebellar structures that derive from the $E n-1$-expressing brain region, suggesting that En-1 is required for the specification, survival, and differentiation of these neural precursors (Wurst et al., 1994). In contrast, loss of En-1 function in the ventral ectoderm of the developing limb does not lead to loss of En-1-expressing ectodermal cells (C. Loomis and A. Joyner, unpublished observations), but instead results in an alteration of ventral ectoderm and mesoderm cell fate and limb patterning (Loomis et al., 1996).

To study the fate of En-1-expressing cells in the spinal cord of En-1 mutants, we analyzed $\beta$-gal expression in homozygous $E n-1^{1 \mathrm{ki} / 1 \mathrm{ki}}$ and compound heterozygous null mutant En-1 ${ }^{1 \mathrm{ki} / \mathrm{hd}}$ embryos at various stages. In these mice, the targeting of lac $Z$ into the first exon of En-1 results in the disruption of En-1 while simultaneously providing a marker for En-1-expressing cells. This allele results in a total loss of En-1 function, because the mutant seems to be morphologically the same as null En-1 hd/hd mutants and En-1 protein expression is not detected in the spinal cord with anti-En antibodies (data not shown).

At $9.5-10.5 \mathrm{dpc}$, expression of $\beta$-gal in En-1 ${ }^{1 \mathrm{ki} / 1 \mathrm{ki}}$ mice was detected in the same region of the ventral IZ as in normal heterozygous littermates at all rostrocaudal levels (Fig. $8 a$ ). Thus, En-1 expression is initiated normally during the early phase of its

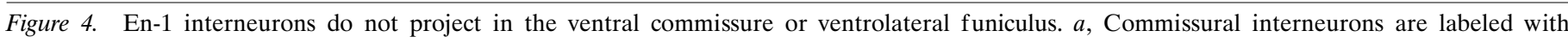

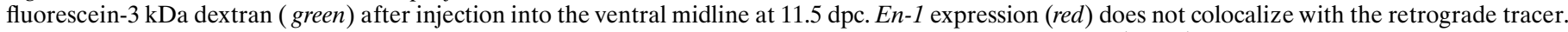

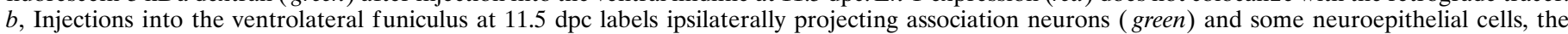

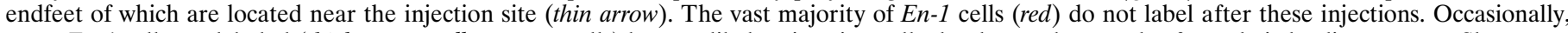

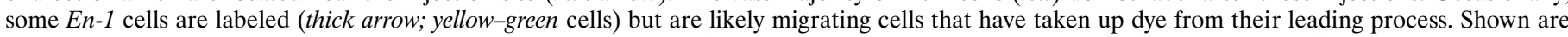

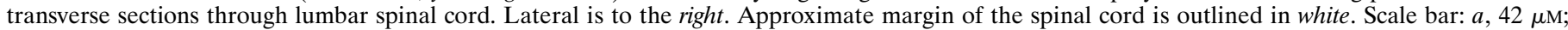
$b, 50 \mu \mathrm{M}$.

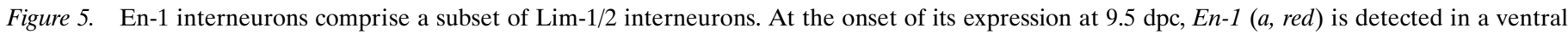

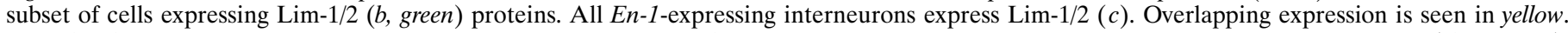

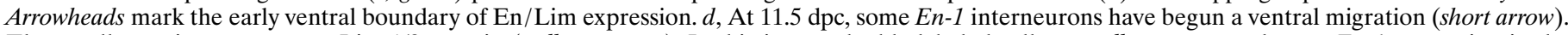

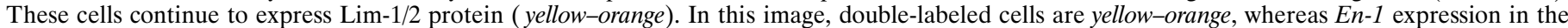

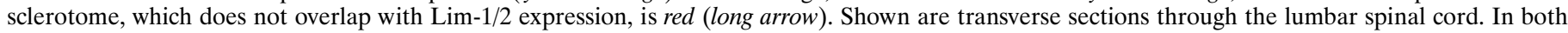
images, lateral is to the right and dorsal to the top. Inset indicates region of spinal cord shown in $a-c$. Scale bars: $a-c, 25 \mu \mathrm{M} ; d, 100 \mu \mathrm{M}$.

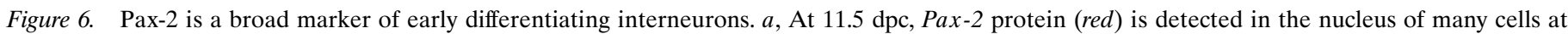

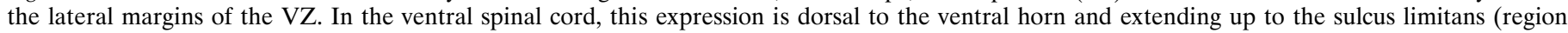

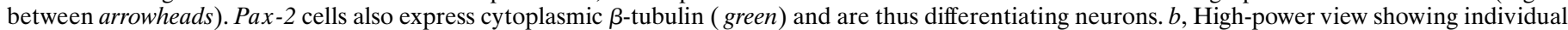

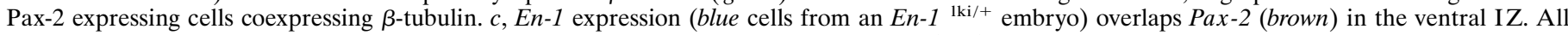
En-1 cells express Pax-2. Boundaries of the ventral Pax-2 domain are indicated by arrowheads. Scale bars: $a, 100 \mu \mathrm{M} ; b$, $c, 50 \mu \mathrm{M}$. 


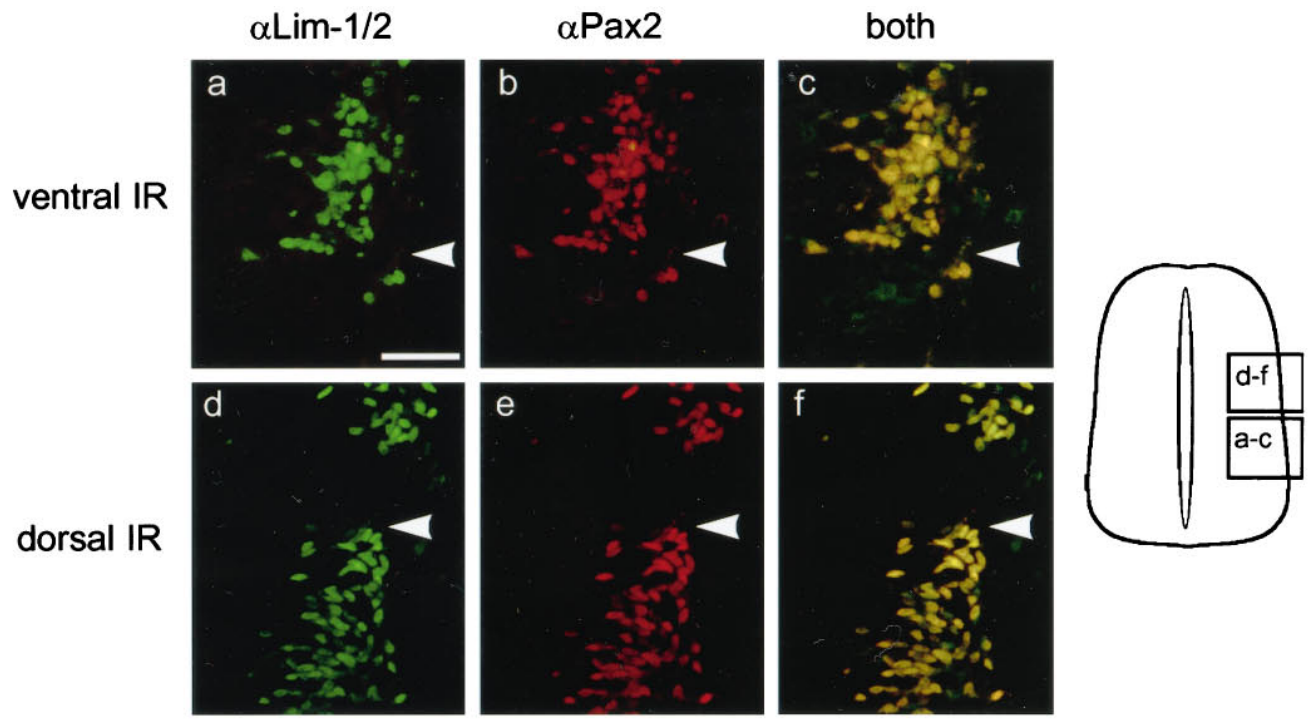

\section{FIGURE 7}

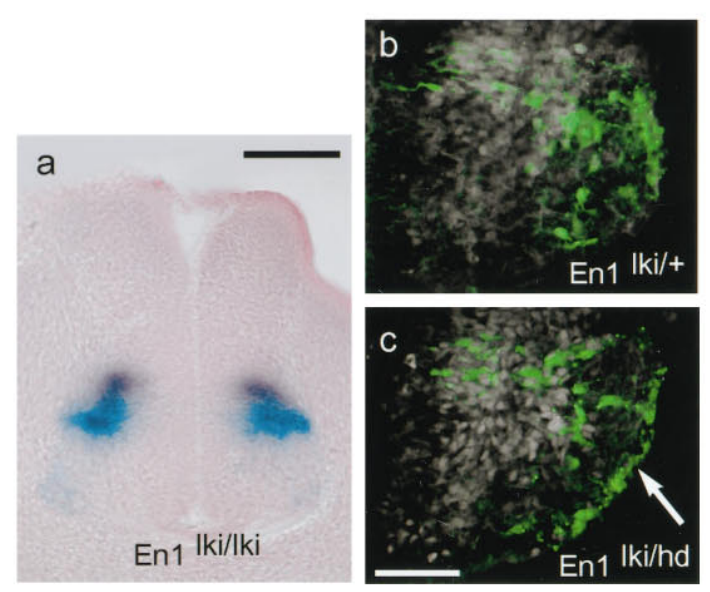

\section{FIGURE 8}

a

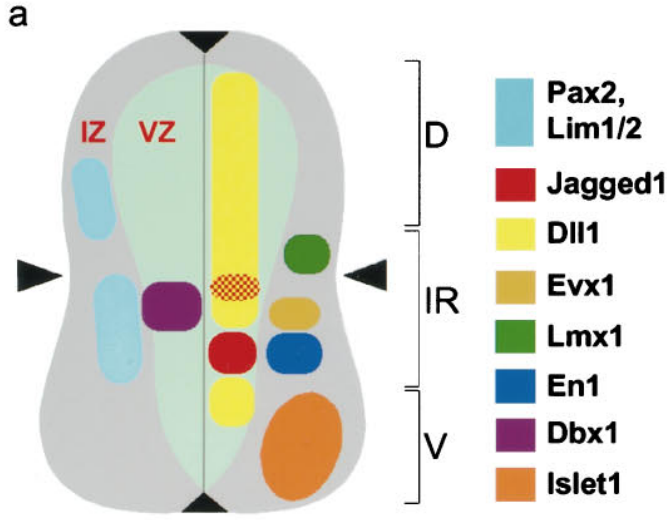

b

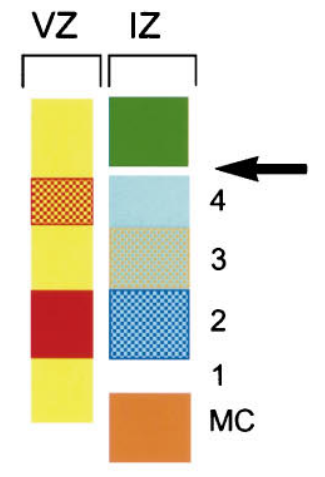

FIGURE 9 
expression in the absence of En-1 gene function in the spinal cord.

The persistence of the En-1-expressing cells in En-1 mutants has allowed for an analysis of their fate in the absence of $E n-1$ function. To control for the expression levels of $\beta$-gal in En-1 1ki/+ heterozygotes and homozygotes, we analyzed staining patterns in En-1 ${ }^{\text {1ki/+ }}$ embryos in comparison with En-1 ${ }^{1 \mathrm{ki} / \mathrm{hd}}$, both of which contain a single copy of lacZ. At $11.5-15.5 \mathrm{dpc}$, the expression of $\beta$-gal in En-1 1ki/hd embryos was seen in cells located near the marginal zone lateral to LMC motoneurons (Fig. 8b,c). $\beta$-gal expression in the spinal cord of these embryos seemed to be indistinguishable from $E n-1^{1 \mathrm{ki} /+}$ littermates at all stages and rostrocaudal levels examined. Thus, En-1-expressing interneurons are able to undergo a normal primary migration out of the VZ zone, as well as a secondary migration ventrally, in the absence of En-1 gene function.

We then set out to determine whether En-1 expression was required for the normal development and differentiation of interneurons in En-1 ${ }^{1 \mathrm{ki} / \mathrm{lki}}$ embryos. One possibility is that $E n-1$ is required to specify the identity of En-1 interneurons or their neighbors; in its absence, these cells may adopt other fates. To test this possibility we analyzed the expression of markers of nearby cell types in En-1 ${ }^{\text {lki/lki }}$ mice. Using double-labeling, we found that both $E v x-1$ (Fig. $8 a$ ) and Islet-1/2 (data not shown) staining patterns in $E n-1^{1 \mathrm{ki} / 1 \mathrm{ki}}$ embryos were similar to controls. These findings revealed that En-1 interneurons do not adopt the fates of more ventral or dorsal cell types, as marked by the expression of two genes specifically found in populations of cells close to En-1-expressing interneurons. We have also examined the expression of Dbx-1, Jagged-1, and Lmx-1 in En-1 mutants and found them to be similar to normal embryos at 10.5-12.5 dpc (data not shown). Together, these results show that the function of En-1 is not required non-cell-autonomously to initiate normal gene expression in nearby cells as assayed by the expression of genes that mark distinct cell types or domains in the IR, nor is it required cell-autonomously to prevent En-1-expressing interneurons from adopting neighboring phenotypes.

We also analyzed the expression of markers that are expressed in En-1 interneurons in En- ${ }^{1 \mathrm{ki} / \mathrm{lki}}$ mice. Both Lim-1/2 and Pax-2 expression were detected in the cells expressing $\beta$-gal in En-1 ${ }^{1 \mathrm{ki} / \mathrm{lki}}$ embryos, as in their heterozygous littermates (data not shown). These findings suggest that Lim-1/2 and Pax-2 may be upstream or in an independent pathway to $E n-1$ in ventral interneurons.

Finally, it has been shown in the grasshopper that ventral nerve cord neuroblasts require En function to undergo a switch between generating glial and neuronal daughters (Condron et al., 1994). We were able to detect the neuron-specific intermediate

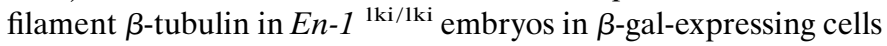
(data not shown); therefore, it is not likely that En-1 serves a similar function to determine glial versus neuronal fates in the mouse.

The persistence of En-1-expressing interneurons in En-1 mutant mice reveals that En-1 function is not required for several facets of early interneuron differentiation, namely cell migration and gene expression, nor is it required for patterning of adjacent cell types. These findings point to a later primary role for En-1 in determining interneuron function in the mouse spinal cord. We have also examined $\beta$-gal expression in En-1 ${ }^{1 \mathrm{ki} / \mathrm{lki}}$ embryos at 15.5 and $17.5 \mathrm{dpc}$ and found that En-1 interneurons persist even at these later embryonic stages (data not shown). Thus it will be possible to study the later development of these cells and of the spinal cord in general in the absence of En-1 function.

\section{DISCUSSION}

In this study, we have focused on the early development of the most abundant population of cells in the vertebrate spinal cord: interneurons. We have found that differentiating interneurons express unique transcription factors in distinct domains along the $\mathrm{d} / \mathrm{v}$ axis. This analysis shows that differentiating interneurons in the spinal cord are organized into at least four $\mathrm{d} / \mathrm{v}$ domains, based on differential gene expression, ventral to the sulcus limitans. The correspondence of these four domains to the expression domains of the Notch ligands Jagged -1 and Dll-1 in the VZ raises the possibility that Notch-mediated lateral inhibition could play a role in patterning differentiation of neurons along this axis. We have summarized the expression patterns studied in this paper in Figure 9. Finally, we have shown that early interneuron development in the En-1 mutant seems normal in many respects, including d/v gene expression patterns, En-1 cell migration and projections, and overall spinal cord morphology. We cannot conclude that loss of En-1 does not have any adverse effect on spinal cord development, because of the lack of specific independent markers for En-1-expressing interneurons or identified target genes or analysis of later interneuron function. Taken together, our results suggest that the early onset of transcription factor expression in differentiating interneurons may serve a later function in distinguishing like groups of cells in this broad class of neuron.

\section{$\leftarrow$}

Figure 7. Lim-1/2 and Pax-2 proteins are coexpressed in early differentiating cells of the ventral IR. Sections through midthoracic spinal cord at 9.5 dpc stained with antibodies to Lim-1/2 (a,d, green) and Pax-2 (b, e, red). $a-c$, In the ventral IR, Lim-1/2 and Pax-2 expression overlaps in cells located dorsal to the motor column (boundary indicated by arrowheads). $d-f$, In the region of the sulcus limitans (arrowhead), the expression of Lim-1/2 and Pax- 2 is coincident in the ventral IR ventral to the sulcus. The dorsal domain of Lim-1/2 and Pax-2 expression is seen at the top of these figures. Lateral is to the right, dorsal to the top in all figures. Schematic at right indicates areas shown in corresponding figure rows. Scale bar, $25 \mu \mathrm{M}$.

Figure 8. En-1 and Evx-1 interneurons do not require En-1 function for their survival or early differentiation. $a$, Both En-1 (blue $\beta$-gal staining) and Evx-1 (purple) expression is initiated normally in En-1 ${ }^{1 \mathrm{ki} / \mathrm{lki}}$ embryos at $10.5 \mathrm{dpc}$. $b$, In a wild-type En-1 ${ }^{\mathrm{lki} /+}$ embryo at $11.5 \mathrm{dpc}, \beta$-gal expression ( green) (detected with antibodies to $\beta$-gal) is seen in En-1 interneurons migrating out of the VZ and ventrally. $c$, In En-1 1ki/hd embryos at the same stage, $\beta$-gal expression (green) is virtually identical to that of wild-type embryos. Shown are transverse sections through the lower thoracic cords. Lateral is to the right in $b$ and $c$. Scale bars: $a, 100 \mu \mathrm{M} ; b, c, 50 \mu \mathrm{M}$.

Figure 9. a, Summary of the expression patterns of genes in the intermediate region of the spinal cord at 10.5-11.5 dpc. Green shading denotes the ventricular zone $(V Z)$, gray shading the intermediate zone (IZ). Arrowheads indicate the position of the developing sulcus limitans. $b$, Schematic highlighting overlapping expression patterns in differentiating neurons of the IZ and the corresponding domains of Jagged-1 and Dll-1 in the VZ. Four distinct regions of gene expression are seen dorsal to the motor column $(M C)$ and extending up to the sulcus limitans (arrow). These domains are numbered 1-4 from ventral to dorsal. Overlapping expression domains are shown by checkerboard patterns. 


\section{Territories of gene expression in differentiating interneurons}

Our analysis has revealed the existence of a number of distinct domains of gene expression in differentiating interneurons, primarily in the ventral spinal cord. Lim-1/2 and Pax-2 are expressed the most widely, initially in a region beginning dorsal to the motor column and extending to the sulcus limitans. Within this domain, $E n-1$ and $E v x-1$ are expressed, with En-1 marking the early ventral boundary of Lim/Pax expression, whereas $E v x-1$ is immediately dorsal to $E n-1$ but not extending to the sulcus limitans. Together, with two domains located between En-1 and Isl-1 and $E v x-1$ and $L m x-1$, at least four distinct domains of gene expression exist in the IR ventral to the sulcus limitans (Fig. 9b). Lmx-1 expression marks a population of cells located immediately dorsal to the sulcus limitans. This gene may mark the ventral limit of the dorsal territory of cell differentiation in the spinal cord and indicates that the dorsal IR is also divided into discrete domains of cell differentiation.

The organization of domains of gene expression along the $d / v$ axis suggests that they may arise as a result of mechanisms that are known to influence cell fates along this axis: Shh and bone morphogenetic protein signaling from ventral and dorsal regions, respectively. Shh has been shown to be an important determinant of ventral cell fates in vertebrates (Echelard et al., 1993; Roelink et al., 1994; Marti et al., 1995; Chiang et al., 1996; Ericson et al., 1996). Thus, the domains of expression of genes such as En-1, Evx-1, Jagged-1, and Dbx-1 that are restricted to the ventral spinal cord may be established by Shh signaling. In contrast, the domains of more broadly expressed genes, such as Lim-1/2, Pax-2, and $D l l-1$, which are also expressed dorsally, may not be determined solely by either ventral or dorsal signaling mechanisms alone, or they may be independent of them. These genes instead may play a role in determining local responses to these signals.

Finally, we have found that the expression domains of all genes studied in this paper extend rostrally through the spinal cord into the hindbrain. En-1, Evx-1, and the ventral Jagged-1 domain all share a common rostral boundary of expression at r1-r2. Although subtle differences do exist in the expression of some of these genes in the hindbrain as compared with the spinal cord, for example additional domains of expression, these observations suggest that many or most ventrally derived hindbrain interneurons share common features with interneurons of the spinal cord.

\section{Notch signaling}

Does Notch-mediated lateral inhibition play a role in establishing domains of cell differentiation along the $d / v$ axis in the mouse spinal cord? Our results show that Jagged-1 and Dll-1 are expressed in patterns in the ventral VZ, which corresponds to regions defined by postmitotic gene expression. In particular, the domain of En-1 expression seems to correlate precisely with the ventral Jagged-1 stripe and a Dll-1-negative region throughout the spinal cord and hindbrain, whereas the dorsal Jagged-1 stripe corresponds to the region immediately ventral to the $L m x-1$ expression domain and the sulcus limitans. En-1, Evx-1, and the ventral Jagged-1 stripe also share a rostral expression boundary at the $\mathrm{r} 1-\mathrm{r} 2$ border. The existence of fundamental $\mathrm{d} / \mathrm{v}$ domains of gene expression in differentiating interneurons and the possible role of Notch signaling in generating these patterns is suggested further by recent findings that several mammalian fringe genes are expressed in patterns similar to Dll-1 and complementary to
Jagged-1 (and En-1) expression domains (Johnston et al., 1997; Laufer et al., 1997).

Although their expression initially is confined to the VZ, it has been shown that the Notch ligands Serrate/Jagged and Delta-1 are expressed in postmitotic cells in the chick spinal cord (Myat et al., 1996). The striking correlation of expression domains of En-1 and Jagged-1 suggests that Jagged-1 may be expressed in immature En-1 interneurons as they differentiate. The expression of these genes may not overlap temporally, however, because Jagged-1 expression is rapidly downregulated as cells move out of the VZ (Lindsell et al., 1995), whereas En-1 expression is primarily seen in lateral regions of the VZ. It has been proposed that Notch signaling in vertebrates serves to maintain and allow expansion of precursor cell populations during neurogenesis (Morrison et al., 1997). It remains unclear, however, why Notch ligands are expressed in distinct $\mathrm{d} / \mathrm{v}$ domains in the vertebrate spinal cord if their primary function is to inhibit differentiation by activating widely expressed Notch receptors. Because three Notch genes have been shown to be expressed in the vertebrate spinal cord (Lindsell et al., 1996; Myat et al., 1996), one possibility is that Jagged-1 and Dll-1 may activate Notch receptors with different affinities, resulting in a differential effect on genes downstream of Notch and a patterned effect on cell differentiation.

\section{Role of transcription factors in interneuron development}

What function does the differential expression of transcription factors play in subgroups of developing interneurons? Our results demonstrate that many or most interneurons acquire unique molecular identities during their early differentiation. These identities may be important for specifying and maintaining aspects of interneuron function at later stages of development. In vertebrates, many spinal cord interneurons have been shown to undergo extensive secondary migration in the gray matter (Leber and Sanes, 1995; Lu et al., 1996) (this study). Thus, it may be crucial for groups of neurons in the IR to establish common identities at early developmental stages, when spatially influenced mechanisms of fate determination may function, to maintain these identities during the widespread mixing brought about by migration in the maturing spinal cord.

Our analysis of the expression of genes in closely related cells along the $\mathrm{d} / \mathrm{v}$ axis in the En-1 mutant shows that En-1 is not required to generate the pattern of interneuron cell differentiation along this axis, including En-1 interneurons. This conclusion is based on the observation that adjacent cells express appropriate markers in the En-1 mutant and that En-1 cells do not require $E n-1$ function for their differentiation, nor do they adopt the fate of adjacent cell types. Although we have not identified markers specific to En-1 interneurons, we have determined that En-1 cells express the more general ventral interneuron markers Lim-1/2 and Pax- 2 in both normal and En-1 mutant spinal cords. Thus, it seems that $E n-1$ expression is downstream of the mechanisms that control early $\mathrm{d} / \mathrm{v}$ patterning in the ventral spinal cord.

It is likely that many or all phenotypic characteristics of interneurons are ultimately controlled by different transcription factors that are expressed in subgroups of interneurons in the spinal cord. In the mature vertebrate spinal cord, functionally similar classes of interneurons are generally found in localized regions of the gray matter (Thomas and Wilson, 1965; Jankowska and Lindstrom, 1972). It has been shown that subsets of motoneurons express unique combinations of LIM-domain genes, which corre- 
late with their initial axon projection patterns (Tsuchida et al., 1994). Because in general neuronal projections are initiated early and are similar for closely related groups of cells (Yaginuma et al., 1990; Silos-Santiago and Snider, 1992, 1994; Eide and Glover, 1996), it is possible that the expression of some transcription factors in groups of interneurons may be important in specifying early projection patterns. Consistent with this is the observation that En-1-expressing interneurons seem to share similar projections in the spinal cord. Although we have not systematically studied the projections of En-1 interneurons in En-1 mutants, we have observed that they do not alter their normal projections to become commissural or ipsilateral/association interneurons in the absence of $E n-1$ (data not shown). Thus, if $E n-1$ specifies the connectivity or projections of these neurons it likely does so on a much finer scale than studied here. It is also possible that En-1 or other region-specific patterns of gene expression play a role in organizing afferent inputs to groups of related interneurons.

Taken together, these studies provide a set of marker genes for studying early $\mathrm{d} / \mathrm{v}$ patterning at a fine scale in normal and mutant embryos, and for determining the influence of secreted inducing factors on this process. Furthermore, this analysis suggests that some of these genes may play critical roles in early or late interneuron development.

\section{REFERENCES}

Bastian H, Gruss P (1990) A murine even-skipped homologue, Evx 1, is expressed during early embryogenesis and neurogenesis in a biphasic manner. EMBO J 9:1839-1852.

Bettenhausen B, Hrabe de Angelis M, Simon D, Guenet J-L, Gossler A (1995) Transient and restricted expression during mouse embryogenesis of Dll1, a murine gene closely related to Drosophila Delta. Development 121:2407-2418.

Chiang C, Litingtung Y, Lee E, Young KE, Corden JL, Westphal H, Beachy PA (1996) Cyclopia and defective axial patterning in mice lacking Sonic hedgehog gene function. Nature 383:407-413.

Condron BG, Patel NH, Zinn K (1994) engrailed controls glial/neuronal cell fate decisions at the midline of the central nervous system. Neuron 13:541-554.

Davis CA, Joyner AL (1988) Expression patterns of the homeoboxcontaining genes En-1 and En-2 and the proto-oncogene int-1 diverge during mouse development. Genes Dev 2:1736-1744.

Davis CA, Holmyard DP, Millen KJ, Joyner AL (1991) Examining pattern formation in mouse, chicken and frog embryos with an Enspecific antiserum. Development 111:287-298.

Dressler GR, Deutsch U, Chowdhury K, Nornes HO, Gruss P (1990) $\mathrm{Pax} 2$, a new murine paired-box-containing gene and its expression in the developing excretory system. Development 109:787-795.

Dush MK, Martin GR (1992) Analysis of mouse Evx genes. Evx-1 displays graded expression in the primitive streak. Dev Biol 151:273-287.

Echelard Y, Epstein DJ, St-Jacques B, Shen L, Mohler J, McMahon JA, McMahon AP (1993) Sonic hedgehog, a member of a family of putative signaling molecules, is implicated in the regulation of CNS polarity. Cell 75:1417-1430.

Eide AL, Glover JC (1996) Development of an identified spinal commissural interneuron population in an amniote: neurons of the avian Hofmann nuclei. J Neurosci 16:5749-5761.

Ericson J, Morton S, Kawakami A, Roelink H, Jessell TM (1996) Two critical periods of sonic hedgehog signaling required for the specification of motor neuron identity. Cell 87:661-673.

Fujii T, Pichel J, Taira M, Toyama R, Dawid I, Westphal H (1994) Expression patterns of the murine LIM class homeobox gene lim 1 in the developing brain and excretory system. Dev Dyn 199:73-83.

Gratzner HG (1982) A new reagent for detection of DNA replication. Science 218:474-475.

Hanks M, Wurst W, Anson-Cartwright L, Auerbach AB, Joyner AL (1995) Rescue of the En-1 mutant phenotype by replacement of En-1 with En-2. Science 269:679-682.
Jankowska E, Lindstrom S (1972) Morphology of interneurones mediating Ia reciprocal inhibition of motoneurones in the spinal cord of the cat. J Physiol (Lond) 226:805-823.

Jankowska E, Lundberg A (1981) Interneurones in the spinal cord. Trends Neurosci 4:230-233.

Johnston SH, Rauskolb C, Wilson R, Prabhakaran B, Irvine KD, Vogt TF (1997) A family of mammalian Fringe signaling molecules implicated in boundary determination and the Notch pathway. Development 124:2245-2254.

Joyner AL, Kornberg T, Coleman KG, Cox DR, Martin GR (1985) Expression during embryogenesis of a mouse gene with sequence homology to the Drosophila engrailed gene. Cell 43:29-37.

Knecht AK, Good PJ, Dawid IB, Harland RM (1995) Dorsal-ventral patterning and differentiation of noggin-induced neural tissue in the absence of mesoderm. Development 121:1927-1936.

Lance-Jones C (1982) Motoneuron cell death in the developing lumbar spinal cord of the mouse. Dev Brain Res 4:473-479.

Laufer E, Dahn R, Orozco OE, Yeo C-Y, Pisenti J, Henrique D, Abbott UK, Fallon JF, Tabin C (1997) Expression of Radical fringe in limbbud ectoderm regulates apical ectodermal ridge formation. Nature 386:366-373.

Leber SM, Sanes JR (1995) Migratory paths of neurons and glia in the embryonic chick spinal cord. J Neurosci 15:1236-1248.

Lee MK, Tuttle JB, Rebhun LL, Cleveland DW, Frankfurter A (1990) The expression and posttranslational modification of a neuron-specific $\beta$-tubulin isotype during chick embryogenesis. Cell Motil Cytoskeleton 17:118-132.

Lindsell CE, Shawber CJ, Boulter J, Weinmaster G (1995) Jagged: a mammalian ligand that activates Notch1. Cell 80:909-917.

Lindsell CE, Boulter J, diSibio G, Gossler A, Weinmaster G (1996) Expression patterns of Jagged, Delta1, Notch1, Notch2, and Notch3 genes identify ligand-receptor pairs that may function in neural development. Mol Cell Neurosci 8:14-27.

Loomis C, Harris E, Michaud J, Wurst W, Hanks M, Joyner A (1996) The mouse engrailed-1 gene and ventral limb patterning. Nature 382:360-363.

Lu S, Shashikant CS, Ruddle FH (1996) Separate cis-acting elements determine the expression of mouse $D b x$ gene in multiple spatial domains of the central nervous system. Mech Dev 58:193-202.

Marti E, Bumcroft D, Takada R, McMahon A (1995) Requirement of $19 \mathrm{~K}$ form of Sonic hedgehog for induction of distinct ventral cell types in CNS explants. Nature 375:322-325.

Morrison SJ, Shah NM, Anderson DJ (1997) Regulatory mechanisms in stem cell biology. Cell 88:287-298.

Myat A, Henrique D, Ish-Horowicz D, Lewis J (1996) A chick homologue of Serrate and its relationship with Notch and Delta homologues during central neurogenesis. Dev Biol 174:233-247.

Nagy A, Rossant J, Nagy R, Abramow-Newerly W, Roder JC (1993) Derivation of completely cell culture-derived mice from early-passage embryonic stem cells. Proc Natl Acad Sci USA 90:8424-8428.

Nornes HO, Carry M (1978) Neurogenesis in spinal cord of mouse: an autoradiographic analysis. Brain Res 159:1-16.

Nornes HO, Dressler GR, Knapik EW, Deutsch U, Gruss P (1990) Spatially and temporally restricted expression of Pax2 during murine neurogenesis. Development 109:797-809.

Nowakowski RS, Lewin SB, Miller MW (1989) Bromodeoxyuridine immunohistochemical determination of the lengths of the cell cycle and DNA-synthetic phase for anatomically defined population. J Neurocytol 18:311-318.

Parr BA, Shea MJ, Vassileva G, McMahon AP (1993) Mouse Wnt genes exhibit discrete domains of expression in the early embryonic CNS and limb buds. Development 119:247-261.

Pfaff SL, Mendelsohn M, Stewart CL, Edlund T, Jessell TM (1996) Requirement for LIM homeobox gene Isl1 in motor neuron generation reveals a motor neuron-dependent step in interneuron differentiation. Cell 84:309-320.

Roelink H, Augsburger A, Heemskerk J, Korzh V, Norlin S, Ruiz i Altaba A, Tanabe Y, Placzek M, Edlund T, Jessell TM, Dodd J (1994) Floor plate and motor neuron induction by vhh-1, a vertebrate homolog of hedgehog expressed by the notochord. Cell 76:761-775.

Shiga T, Oppenheim RW (1991) Immunolocalization studies of putative guidance molecules used by axons and growth cones of intersegmental interneurons in the chick embryo spinal cord. J Comp Neurol 310:234-252.

Shoji H, Ito T, Wakamatsu Y, Hayasaka N, Ohsaki K, Oyanagi M, 
Kominami R, Kondoh H, Takahashi N (1996) Regionalized expression of the $D b x$ family of homeobox genes in the embryonic CNS of the mouse. Mech Dev 56:25-39.

Silos-Santiago I, Snider WD (1992) Development of commissural neurons in the embryonic rat spinal cord. J Comp Neurol 325:514-526.

Silos-Santiago I, Snider WD (1994) Development of interneurons with ipsilateral projections in embryonic rat spinal cord. J Comp Neurol 342:221-231.

Tanabe Y, Jessell TM (1996) Diversity and pattern in the developing spinal cord. Science 274:1115-1123.

Thomas RC, Wilson VJ (1965) Precise localization of Renshaw cells with a new marking technique. Nature 206:211-213.
Tsuchida T, Ensini M, Morton SB, Baldassarre M, Edlund T, Jessell TM, Pfaff SL (1994) Topographic organization of motor neurons defined by expression of LIM homeobox genes. Cell 79:957-970.

Wurst W, Auerbach AB, Joyner AL (1994) Multiple developmental defects in Engrailed-1 mutant mice: an early mid-hindbrain deletion and patterning defects in forelimbs and sternum. Development 120:2065-2075.

Yaginuma H, Shiga T, Homma S, Ishihara R, Oppenheim RW (1990) Identification of early developing axon projections from spinal interneurons in the chick embryo with a neuron specific $\beta$-tubulin antibody: evidence for a new "pioneer" pathway in the spinal cord. Development 108:705-716. 